\title{
The ST segment of the ambulatory electrocardiogram in a normal population
}

\author{
RAVINDER S KOHLI, PETER M M CASHMAN, AVIJIT LAHIRI, \\ EDWARD B RAFTERY
}

From the Department of Cardiology and Division of Clinical Sciences, Northwick Park Hospital and Clinical Research Centre, Harrow

SUMMARY The behaviour of the ST segment in everyday life was studied by ambulatory electrocardiography in 111 normal volunteers. Fifteen were excluded because of abnormal exercise $\dot{2}$ responses (10 subjects) and significant postural ST segment shifts (five subjects). This left 62 men and 34 women, mean (SD) age 40.5 (12.6) years (range 20-67 years). Ambulatory monitoring of leads CM5 and CC5 for 24 hours was followed by a maximal treadmill exercise test. The tapes of the ambulatory monitoring were analysed by a computer aided system. The computer printed $\vec{c}$ trend plots of the ST segment (measured both at the J point and at J $+60 \mathrm{~ms}$ ) to detect episodes of ST segment elevation and depression, which were confirmed by visual analysis of real time print- $\vec{\varphi}$ outs. Twelve subjects showed "ischaemic" ST segment depression and nine subjects showed ST $\infty$ segment elevation. Eight people with ambulatory ST segment changes were studied during exercise by radionuclide ventriculography and thallium-201 imaging scans. Although seven of the eight thallium studies were normal, radionuclide ventriculography showed functional impairment $\bar{\partial}$

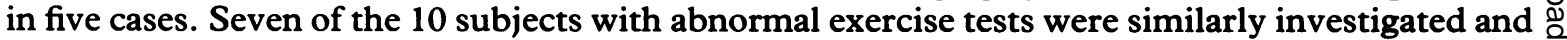
their results followed the same pattern, with normal thallium images in six and functional $\AA$ impairment in four. Ambulatory electrocardiography was repeated in 20 people after a median of $\overrightarrow{\vec{O}}$ 20 days. The ST segment changes were reproducible.

ST segment changes of an apparently ischaemic nature occur even in a carefully defined normal population but they do not necessarily represent latent clinically significant coronary artery disease. This indicates that ST segment changes seen in patients with known obstructive coronary artery disease should be interpreted with caution.

Horizontal and downsloping depression of the ST segment of the electrocardiogram is a well established marker of myocardial ischaemia ${ }^{1}$ that may or may not be accompanied by angina. ${ }^{2-5} \mathrm{~A}$ wide variety of physiological events ${ }^{67}$ and drugs can, however, produce ST segment changes identical to those interpreted as indicating myocardial ischaemia.

Ambulatory monitoring of the electrocardiogram for periods of ST segment depression has been widely used for the detection and quantification of ischaemia..$^{3-5}$ Some direct recording systems produce low frequency phase distortion, however, which mimics ischaemic ST depression ${ }^{8}$ and the criteria

Requests for reprints to Dr Edward B Raftery, Department of Cardiology, Northwick Park Hospital and Clinical Research Centre, Watford Road, Harrow, Middlesex HA1 3UJ.

Accepted for publication 1 December 1987 used to assess the magnitude and duration of ischaemic ST change remain empirical.

The results of previous studies on "normal" 욱 populations were contradictory. Possible reasons for $\frac{7}{2}$ this include biased selection of subjects, ${ }^{10}$ lack of physical screening," and failure to exclude "vaso- No regulatory" and postural ST segment changes. ${ }^{1011}$

We studied ambulatory ST segment deviation in a carefully selected normal population to define the $\omega$ variety, duration, and repeatability of ST segment deviation during 24 hours of normal activity.

\section{Patients and methods}

We selected 116 people from the local population by taking every tenth record card from the index files of three local general practices. We excluded cards $\mathbb{\AA}$ indicating any history or symptoms suggestive of 
cardiovascular disease. Informed written consent was obtained from all volunteers, and the project was approved by the hospital ethics committee.

The subjects were screened by physical examination, a 12 lead electrocardiogram, and a questionnaire on their personal and family histories. Five who were taking medication or had a history suggestive of cardiovascular disease were excluded. We studied the remaining 111 .

\section{RECORDING OF AMBULATORY TAPES}

Orthostatic tests for postural ST segment shifts in the supine, prone, lateral, sitting, and standing positions; the Valsalva manoeuvre; and $60 \mathrm{~s}$ of hyperventilation were performed with a ComputerAssisted System for Exercise (Marquette Electronics Inc.) and we obtained a digital recording of the ST shift to the nearest $0.1 \mathrm{~mm}$. All subjects were then fitted with an Oxford Medilog MR 20 frequency modulated recorder with the bipolar leads CM5 (negative electrode at the manubrium and exploring electrode at LV5) and CC5 (negative electrode at RV6 and exploring electrode at LV5). We were careful with skin preparation and electrode placement and fixing. The electrodes were held in place by a close-fitting elastic vest. The subjects were instructed to use the marker button for timing events such as smoking, driving, and other important activities.

Volunteers were monitored for 24 hours during normal daily activities, and then they performed a symptom-limited graded treadmill exercise test with the same leads and a standard protocol. ${ }^{12}$ An abnormal response was defined as horizontal or downsloping ST depression of $\geqslant 1 \mathrm{~mm}$ that persisted for at least $80 \mathrm{~ms}$ (heart rate $<105 / \mathrm{min}$ ) or $60 \mathrm{~ms}$ (heart rate $>105 / \mathrm{min}$ ) after the $\mathrm{J}$ point. The exercise electrocardiogram leads were simultaneously recorded on the Medilog to enable a retrospective validation of each ambulatory tape.

Twenty volunteers underwent a second 24 hour ambulatory recording with the same equipment after an interval of 1-225 (median 20) days.

\section{ANALYSIS OF AMBULATORY TAPES}

All the tapes were analysed by an updated version of a computer system reported from our laboratory ${ }^{8}$ and also visually by two independent observers.

The computer system, which was based on a modified Pathfinder II analyser (Reynolds Medical, UK) and a MINC 11/23 computer (Digital Equipment Corp.), processed both leads simultaneously, measured ST level at the $J$ point and at $J+60$ or $\mathrm{J}+80 \mathrm{~ms}$, excluded artefact and extrasystoles, and captured patient event marks. The Pathfinder analyser generated a superimposed electrocardiographic display with three bright spots, one of which was manually located on the PR segment to identify the isoelectric point. The second spot was positioned at the J point. The third spot was automatically located $60 \mathrm{~ms}$ after the J point, or $80 \mathrm{~ms}$ if the heart rate fell below 105 beats per minute. The electrocardiogram was continuously scanned which enabled the Pathfinder to flag artefacts and exclude extrasystoles; the operator could also intervene to indicate any artefacts missed by the automatic system. The signals from the Pathfinder were processed by the computer which stored 20 s average values of ST and heart rate on diskette, together with the time, patient event marks, arrhythmia flag, and a marker of artefact detected either automatically or by the operator. The recorded quartz crystal clock ensured accurate timing on each tape.

After we completed the tape scan we retrieved the ST data from the diskette and plotted them as a 24 hour trend together with heart rate, event marks, and an indication of horizontal or downsloping ST segment. Artefact was automatically indicated by lifting of the plotter pen so that misleading data did not appear on the plot. Separate plots were obtained for trends of the $J$ point and of the $(J+60 \mathrm{~ms})$ levels to confirm all suspected downsloping ST depression episodes. Where $(\mathrm{J}+80 \mathrm{~ms})$ values had been stored these were converted to $(\mathrm{J}+60 \mathrm{~ms})$ values by interpolation.

Two independent observers performed further visual analysis by printing out on paper at $25 \mathrm{~mm} / \mathrm{s}$ all episodes of significant or nearly significant ST change, both depression and elevation, seen on the trend plots. A significant episode was defined as $\geqslant 1$ $\mathrm{mm}$ of horizontal or downsloping ST segment depression persisting for at least $60 \mathrm{~ms}$ after the J point and maintained for $\geqslant 1$ minute. Nearly significant episodes were defined as $0.5-1.0 \mathrm{~mm}$ of horizontal or downsloping depression maintained for $\geqslant 1$ minute. For the repeatability study a less stringent criterion was used to obtain more episodes. Here a significant episode was defined as $\geqslant 0.5 \mathrm{~mm}$ of ST depression at $J+60 \mathrm{~ms}$ maintained for $\geqslant 1$ minute. The tapes were also examined for $T$ wave changes; a doubling of the $T$ wave height from the resting value was considered as "peaking". Episodes of $T$ wave flattening and inversion were also assessed.

\section{VALIDATION}

For every subject the tape analyser was validated against the Marquette exercise system by simultaneously recording with the same electrodes a two lead exercise electrocardiogram (CM5/CC5) both on the Medilog tape and on the exercise system. The tape analyser was then used to derive values for one 
minute average ST and heart rate that were compared with corresponding one minute averages extracted from the Marquette data by a special retrieval program.

\section{RADIONUCLIDE INVESTIGATIONS}

We asked volunteers who showed abnormal ST segment depression during ambulatory monitoring or during the exercise test to consent to radionuclide angiography and exercise thallium-201 imaging.

Equilibrium radionuclide angiography was performed at rest and during supine graded ergometric exercise. ${ }^{1314}$ The blood pool was labelled in vivo with stannous pyrophosphate and $740 \mathrm{MBq}$ of technetium- $-99 \mathrm{~m}$. Imaging was carried out with a mobile digital small field of view gammacamera (Elscint) in a modified left anterior oblique view (best septal) with a $10^{\circ}$ to $15^{\circ}$ caudal tilt. We divided the averaged cardiac cycle into 32 frames per cycle at rest and 24 frames per cycle during exercise to provide a high resolution time-activity curve from which the left ventricular ejection fraction was calculated by a semiautomatic algorithm. ${ }^{14}$ We defined failure to increase the ejection fraction by $5 \%$ in the presence of abnormal wall motion as an abnormal response to exercise. The peak filling rate was calculated as the slope of a $100 \mathrm{~ms}$ segment of the time-activity curve around the point of maximal slope before diastasis. ${ }^{13}$

We performed thallium-201 imaging after a symptom limited exercise test. ${ }^{12} \mathrm{~A}$ physician who was unaware of the results of the other investigations analysed all the radionuclide studies.

\section{STATISTICAL ANALYSIS}

Data were expressed as mean (SD). The figures show the standard error of the mean. Analysis of variance was performed for the repeat tapes; for convenience all components of variance were redefined as components of variability by taking the square root.

\section{Results}

We studied 72 men and 39 women (aged 20-67 years) (table 1). We excluded five people because they showed more than $0.5 \mathrm{~mm}$ ST depression in response to orthostatic testing; a further 10 showed a positive response to exercise testing and we analysed their

Table 1 Age and sex distribution of 111 subjects

\begin{tabular}{llll}
\hline Age range & Men & Women & Total \\
\hline $20-29$ & 16 & 13 & 29 \\
$30-39$ & 17 & 6 & 23 \\
$40-49$ & 14 & 8 & 22 \\
$50-59$ & 15 & 9 & 24 \\
$60-67$ & 10 & 3 & 13 \\
\hline
\end{tabular}

data separately (group B, fig 1). The remaining 96 subjects (62 men and 34 women) (aged 45.6 (12.4)) made up group $\mathrm{A}$ (fig 1 ).

SUBGROUP OF SUBJECTS WITH NORMAL

EXERCISE RESPONSE (GROUP A, FIG 1)

Validation of ambulatory tapes (table 2)

We obtained clean exercise recordings from 94 of the 96 subjects for both the Marquette exercise system and the Medilog recorder. In 50, the two systems agreed to within $0.5 \mathrm{~mm}$ in both leads throughout exercise. Analysis of differences (table 2) showed a $\vec{\circ}$ mean (SD) discrepancy of $0.09(0.2) \mathrm{mm}$ on lead $\overrightarrow{\vec{H}}$ CM5 and $0.07(0.2) \mathrm{mm}$ on lead CC5 over a total of ${ }_{\odot}^{\omega}$ 915 one minute mean values. The Marquette system read slightly more positive than the tapes on lead CM5 and more negative on lead CC5. In 41 subjects, agreement was maintained within $1 \mathrm{~mm}$, except at is peak exercise in eight. This group of 41 showed mean $ᄋ$ (SD) discrepancies of $0.09(0.44) \mathrm{mm}$ on CM5 and $0.17(0.43) \mathrm{mm}$ on $\mathrm{CC} 5$ over 777 observations. When $c$ the eight peak exercise results were excluded the remaining 33 showed discrepancies of $0.11(0.37) \overrightarrow{0}$ mm on CM5 and $0.11(0.36) \mathrm{mm}$ on CC5 over a total $\infty_{\infty}^{\infty}$ of 622 one minute mean values. Again, the Marquette system read more positive than the tapes on lead CM5 and more negative on lead CC5. The remaining three tapes showed disagreements of more than $3 \mathrm{~mm}$ that were traced to $Q$ and $S$ wave identification errors in the Marquette system. No significant errors were detected in the tape analyser.

Ambulatory $S T$ depression (groups $A 2$ and A3, fig 1) Twelve subjects $\left(12 \cdot 3^{\circ} \mathrm{o}\right)$ had episodes of significant ST depression (figs 2 and 3). Four women and one man were aged $<40$ years (mean $28.2(4.9)$ ). The remaining five men and two women were aged $\geqslant 40$ (mean 51.4 (7.2)). A total of 31 episodes of ST depression were recorded. There was a range of one to eight episodes per subject (mean 2.5 (2.2)). All 31 episodes were detected in CM5 but only eight were detected in lead CC5. Episodes lasted from one to 32 min (mean 10.0 (9.5) min), with ST segment depression of -0.1 to $-2.8 \mathrm{~mm}$. The mean heart rate during the episodes was $122.1(21.5)$ beats/min (range 80 to 160) (fig 4). All episodes occurred during the daytime and none occurred during sleep. The subjects' diaries provided information corresponding to the time of ST depression for 15 of the 31 episodes. Seven episodes were associated with car driving, two with heavy lifting, two with cycling, two with brisk walking, one with getting dressed in the morning, and one occurred at rest. Four of these 15 episodes were associated with tobacco smoking. The subjects had not made diary entries for the remaining episodes. 


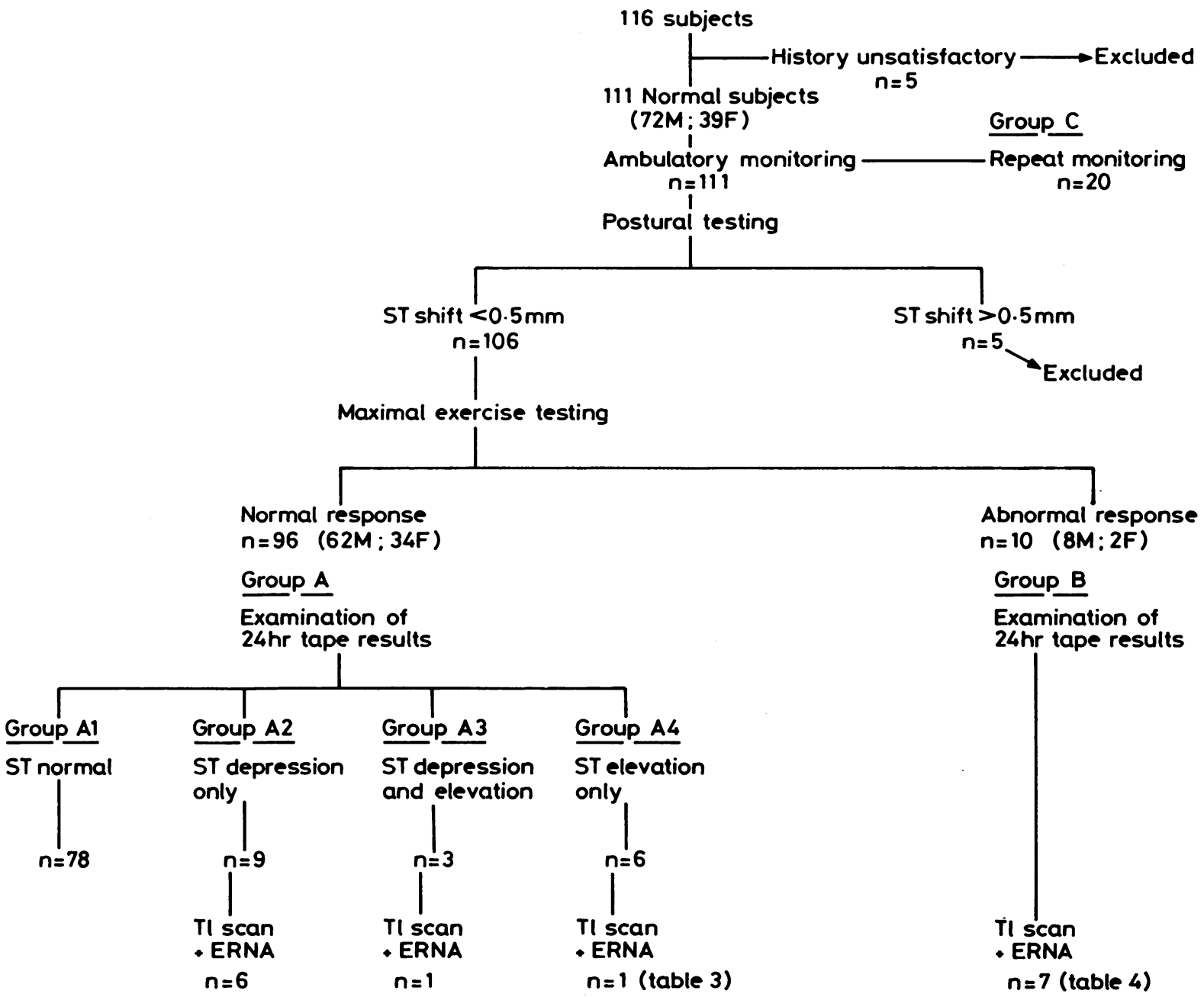

Fig 1 Subject selection and pattern of study. All branches except repeat monitoring are mutually exclusive. ERNA, exercise radionuclide angiography; $T l$, thallium.

Ambulatory ST elevation (groups A3 and A4, fig 1)

In most people there was a slight $(0 \cdot 2-0 \cdot 6 \mathrm{~mm})$ upward shift of the baseline at night. Nine people (six men, three women, aged 21-63 years) showed a more pronounced upward shift in baseline of $0 \cdot 8-1 \cdot 2 \mathrm{~mm}$. The upward trend in the baseline followed the downward trend in the heart rate (fig 5).

Nine $\left(9 \cdot 3^{\circ}\right)$ of the 96 subjects had 28 short distinct episodes of abnormal ST segment elevation 1.0 to $2.5 \mathrm{~mm}$ above the prevailing baseline. They were all men aged $25-57$ years. Five were aged $\leqslant 40$ years (mean 30.4 (5.6)) and four were $>40$ (mean $52 \cdot 2(3 \cdot 7)$ ). The episodes continued for a mean of $25 \cdot 3(22 \cdot 1) \mathrm{min}$ (fig 6). The heart rate ranged from 34 to 78 beats/min (mean $58.1(13.5)$ ) and remained unchanged during the episodes.
$S T$ elevation and depression (group A3, fig 1)

Three subjects (all men) who showed ST segment depression during the day also had episodes of ST segment elevation at night.

\section{$T$ wave changes}

Seventeen individuals showed peaking of the $T$ wave, which was associated with slow heart rates and ST elevation (fig 5). We saw $T$ wave flattening or inversion or both in 17 subjects without ST depression. Four of the subjects with ST depression had associated $T$ inversion (fig 3). Two subjects had both peaking and flattening of the $\mathrm{T}$ wave. In all, $32(33 \%)$ subjects showed $T$ wave changes not associated with significant ST shift. 
Table 2 Validation of ambulatory tape $v$ CASE system: analysis of differences

\begin{tabular}{|c|c|c|c|}
\hline & & \multicolumn{2}{|c|}{$C A S E$-tape, 1 min mean $S T(J)$ values } \\
\hline & CM5 & CC5 & Heart rate (beats/min) \\
\hline \multicolumn{4}{|c|}{ Group 1 (agreement within $0.5 \mathrm{~mm}$ throughout exercise) $n=50$} \\
\hline Mean difference (mm) & 0.089 & -0.073 & -0.02 \\
\hline SD & $0 \cdot 193$ & $0 \cdot 187$ & 3.66 \\
\hline \multirow{2}{*}{\multicolumn{4}{|c|}{ Group 2 (agreement within $0.5 \mathrm{~mm}$ except around peak exercise) $n=16$}} \\
\hline & & & \\
\hline $\begin{array}{l}\text { Mean difference }(\mathrm{mm}) \\
\text { SD }\end{array}$ & 0.143 & -0.009 & $0 \cdot 66$ \\
\hline $\begin{array}{l}\text { SD } \\
\text { No of observations }\end{array}$ & $\begin{aligned} 0.354 \\
278\end{aligned}$ & $0 \cdot 297$ & 300 \\
\hline \multicolumn{4}{|c|}{ Group 3 (agreement within $1 \mathrm{~mm}$ throughout exercise) $\begin{array}{l}255 \\
n=17\end{array}$} \\
\hline Mean difference (mm) & 0.079 & -0.183 & 0.39 \\
\hline SD & $0 \cdot 38$ & 0.38 & $3 \cdot 14$ \\
\hline \multirow{2}{*}{\multicolumn{4}{|c|}{ Group 4 (agreement within $1 \mathrm{~mm}$ except around peak exercise) $n=8$}} \\
\hline & & & \\
\hline $\begin{array}{l}\text { Mean difference }(\mathrm{mm}) \\
\text { SD }\end{array}$ & $\begin{array}{l}0.048 \\
0.634\end{array}$ & $\begin{array}{r}-0.437 \\
0.583\end{array}$ & $\begin{array}{l}-1 \cdot 09 \\
4 \cdot 121\end{array}$ \\
\hline No of observations & 155 & 157 & 168 \\
\hline & All subjects $(n=91)$ & & \\
\hline Mean difference (mm) & 0.092 & -0.121 & $\begin{array}{l}0.075 \\
3.68\end{array}$ \\
\hline No of observations & $\begin{array}{l}0.329 \\
1677\end{array}$ & 1692 & $1830^{3.68}$ \\
\hline
\end{tabular}

CASE, Marquette computer-assisted system for exercise.

Results of radionuclide testing (tables 3 and 4)

Eight of the 18 subjects who showed ST changes on ambulatory monitoring despite a normal exercise test had radionuclide ventriculograms and thallium scanning during exercise. These were six of the nine who had shown ambulatory ST depression alone (group A2), one of the six who had shown ST elevation alone (group A4), and one of the three who had shown both ST depression and elevation (group A3).

The ventriculograms showed evidence of functional impairment in five; left ventricular ejection fraction fell during exercise in two subjects and the resting peak filling rate was at the lower end of nor$\mathrm{mal}^{131516}$ in four. One of these (a woman of 33) also had an abnormal thallium scan showing a small reversible perfusion defect near the upper interventricular septum. The remaining seven exercise thallium scans were normal, as defined both by the absence of a photon-deficient area and by quantitative washout.

\section{SUBGROUP OF SUBJECTS WITH ABNORMAL}

EXERCISE RESPONSE (GROUP B, FIG 1)

Ten people (eight men, two women, aged 42-65 years) had an abnormal exercise response on the treadmill; none complained of chest discomfort and the end point was always fatigue. Five had 16 episodes of ST depression during ambulatory monitoring that lasted for 3-5 minutes at heart rates of 100-160 beats/min and one had ST elevation at night (heart rate $50 / \mathrm{min}$ ). We obtained radionuclide ventriculograms during exercise in seven of the 10 subjects and showed functional impairment in four; the left ventricular ejection fraction did not increase in any of these four and the resting peak filling rate was low in two. Exercise thallium scans performed in six of these subjects were normal, however (table 4).

REPEAT TAPE ANALYSIS (GROUP C, FIG 1) We analysed 40 tapes from this subgroup of $20 \AA$ subjects.

$S T$ baseline levels: repeatability (table 5)

For both leads the difference between day and night was significantly greater than the difference between recordings $(p<0.001)$; this means that the nocturnal shift must be taken into account when computer analysis is performed. Analysing day and night separately, the component of variability within subjects between recordings was significantly less $(p<0.001)$ than that between subjects both for daytime and for night, indicating good individual repeatability of baselines.

\section{$S T$ depression: repeatability (table 6 )}

A total of 136 episodes of $0.5 \mathrm{~mm} \mathrm{ST}$ depression at $\mathrm{J}+60 \mathrm{~ms}$ were detected in lead CM5. The repeatability was good for the total number of episodes detected $(F=3.5 ; \quad p<0.001)$, the maximal ST depression $(F=2.6 ; p=0.03)$, and the heart rate at maximal ST depression $\left(F=7 \cdot 2 ;^{-}\right.$ $\mathrm{p}<0.001$ ). The average duration of episodes was poorly repeatable because the component of $\frac{D}{\mathbb{D}}$ variability between recordings was similar to that $\frac{}{\mathrm{D}}$ between subjects. A similar result was seen for lead $\varrho$ CC5, where 87 episodes were detected. 


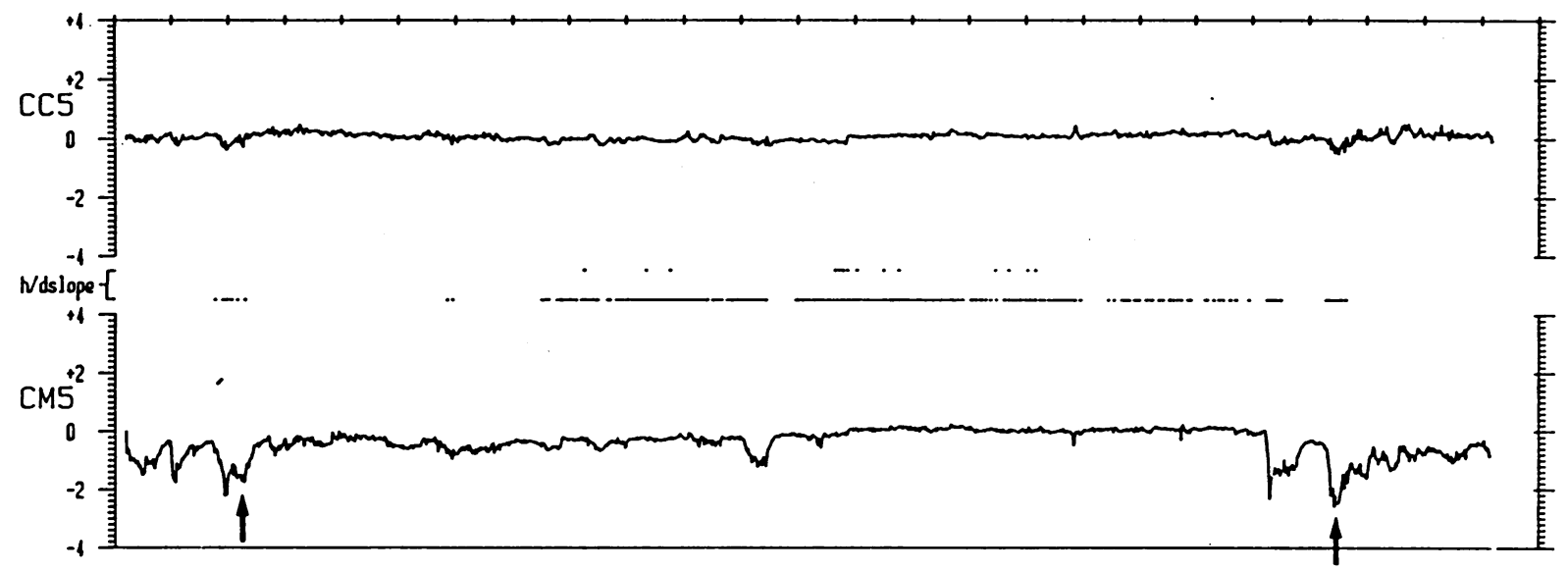

Event $f$.
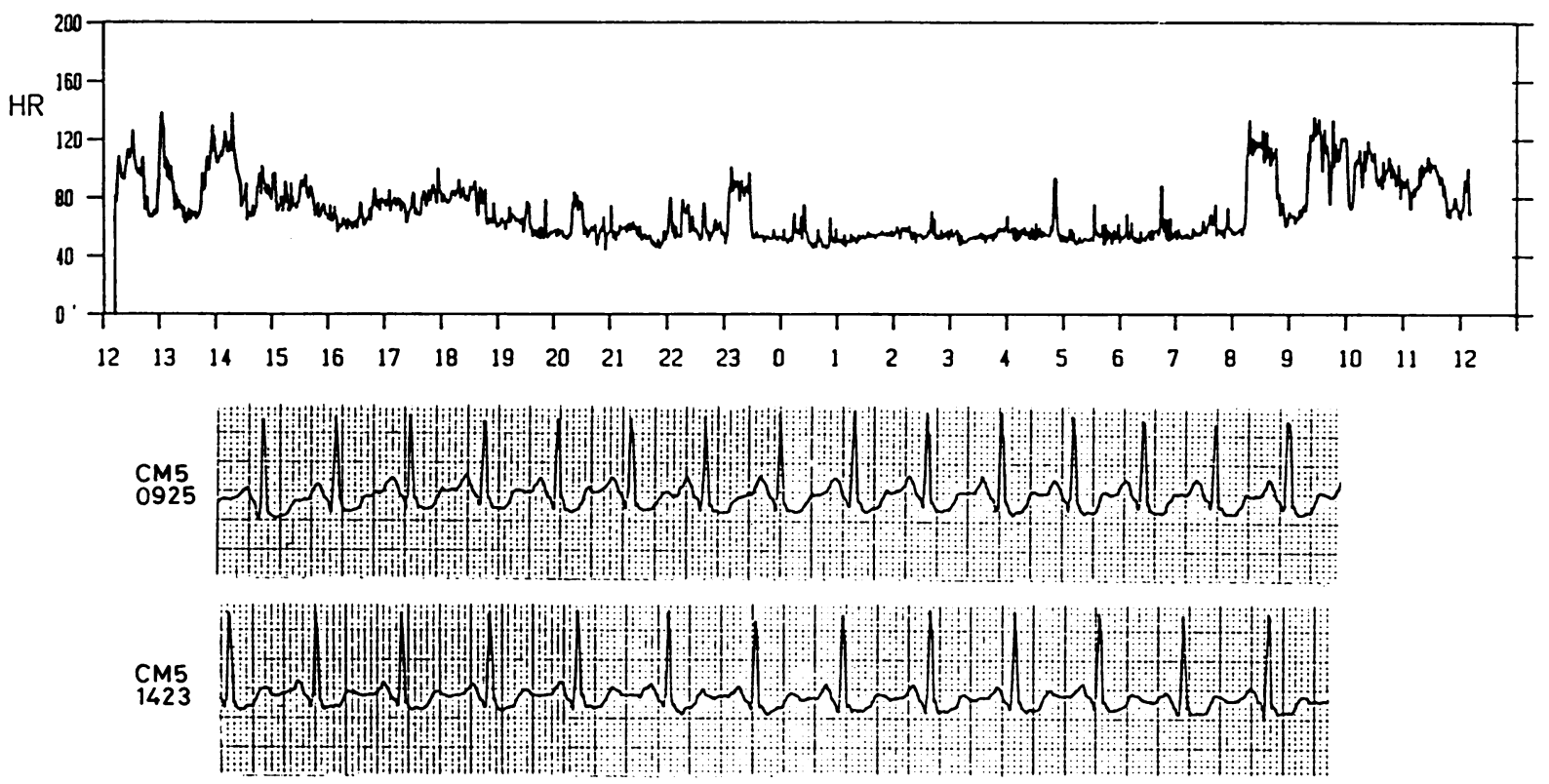

Fig $2 S T$ segment trend chart showing horizontal depression in CM5 at $9.25 \mathrm{~h}$ and $14.23 \mathrm{~h}$.

ST elevation: repeatability

Episodes of ST elevation were too infrequent in this subgroup of 20 subjects to permit a proper analysis of variance. ST elevation occurred on both recordings in only two subjects in lead CC5 and in only one recording in lead CM5.

\section{Discussion}

Ambulatory tape recorders were first introduced for the detection of cardiac arrhythmias ${ }^{17}$ but since then they have also been used to detect episodes of myocardial ischaemia. Investigations of the recorder 


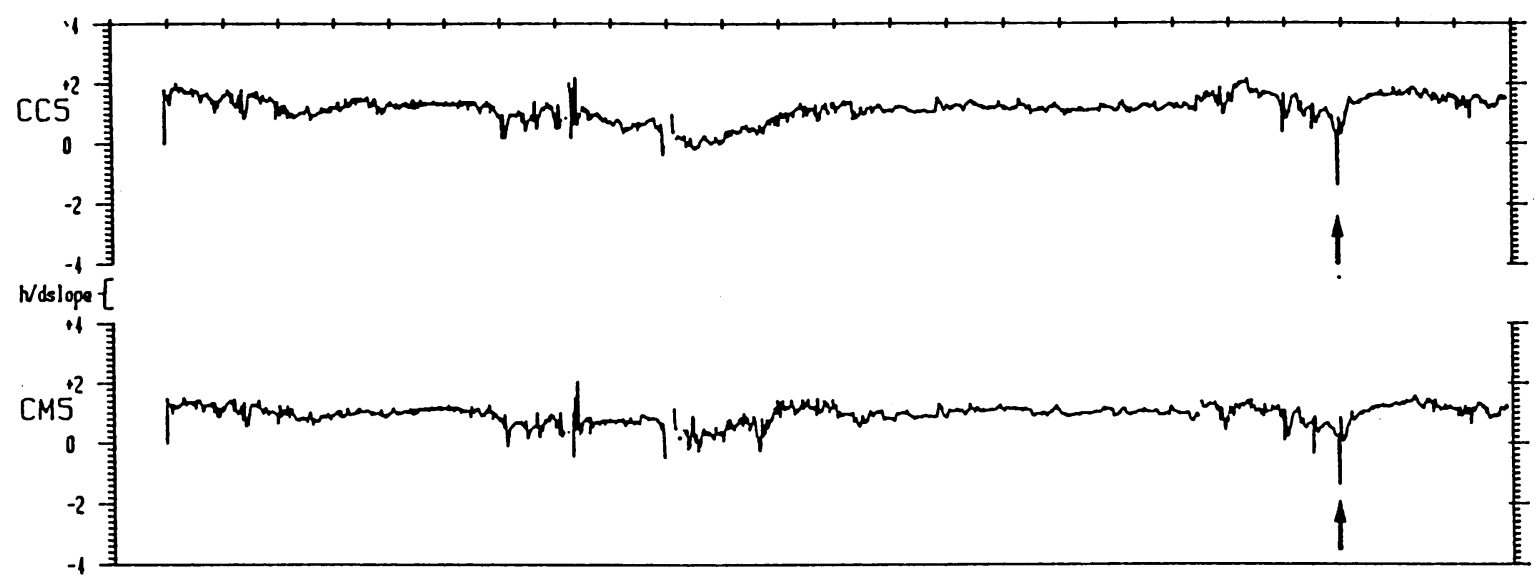

Nrinyth [
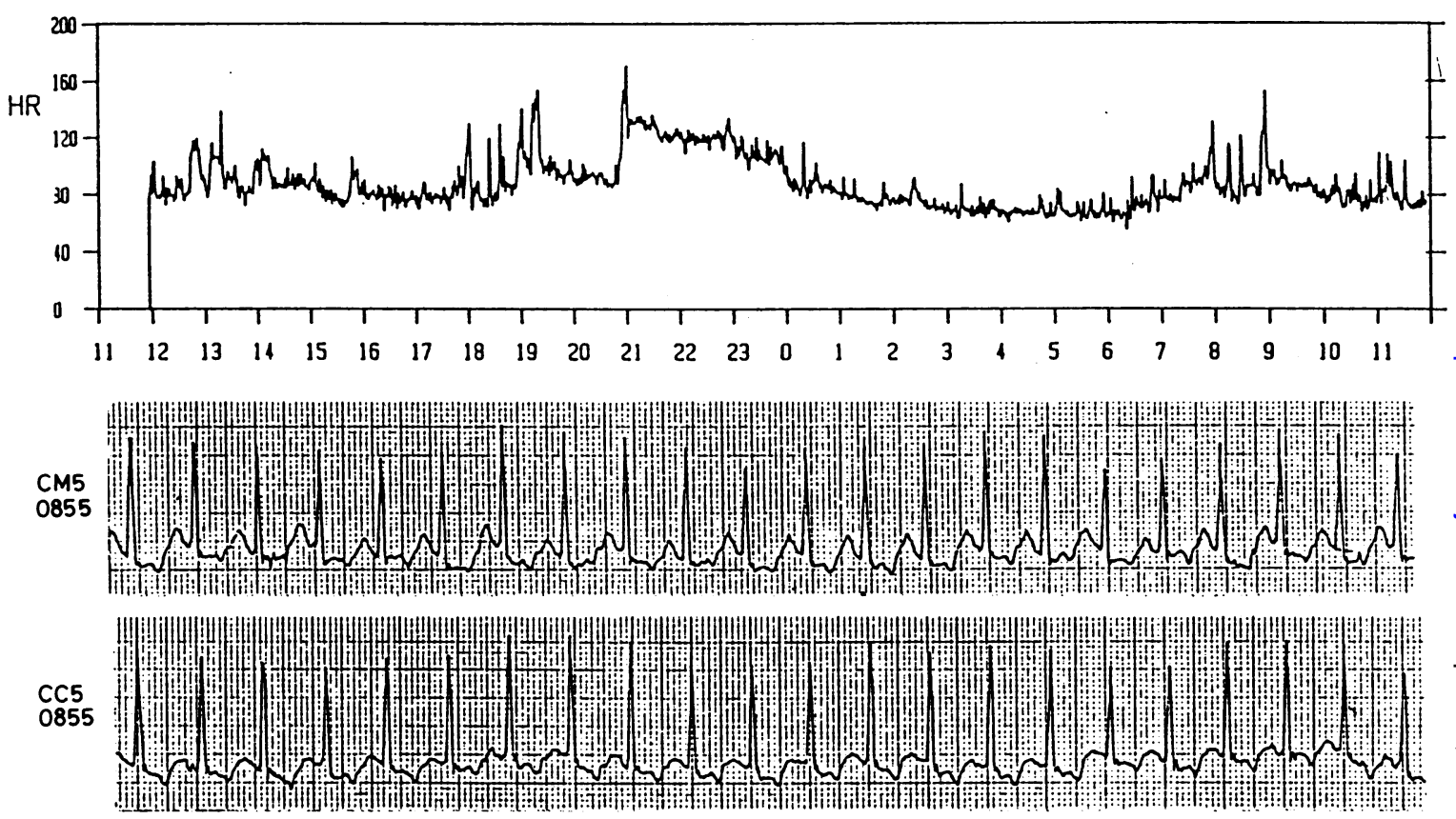

Fig 3 Trend chart showing "ischaemic" ST depression in a young man at 8.55 h during brisk walking.

performance, particularly ST-T fidelity, led to the introduction of frequency modulated recorders for the accurate detection of ST segment shifts..$^{8.1819}$ Reports of "silent myocardial ischaemia" potential dangers ${ }^{3-5} 21$ continue to increase despite the fact that exercise ST deviation is a poor predictor of obstructive coronary artery disease $e^{22}$ and that $\mathrm{ST}^{+}$ changes can be produced by public speaking, ${ }^{23}$ a hot sauna, ${ }^{7}$ gastroscopy, ${ }^{24}$ mitral valve prolapse, ${ }^{25} \frac{\mathrm{D}}{\mathrm{N}}$ neurocirculatory asthenia, ${ }^{26}$ and car driving. ${ }^{27}$ It is $\frac{\widetilde{ }}{\mathrm{O}}$ not clear whether these changes are caused by ischaemia or other mechanisms. 
No of episodes 11222244161112882 .
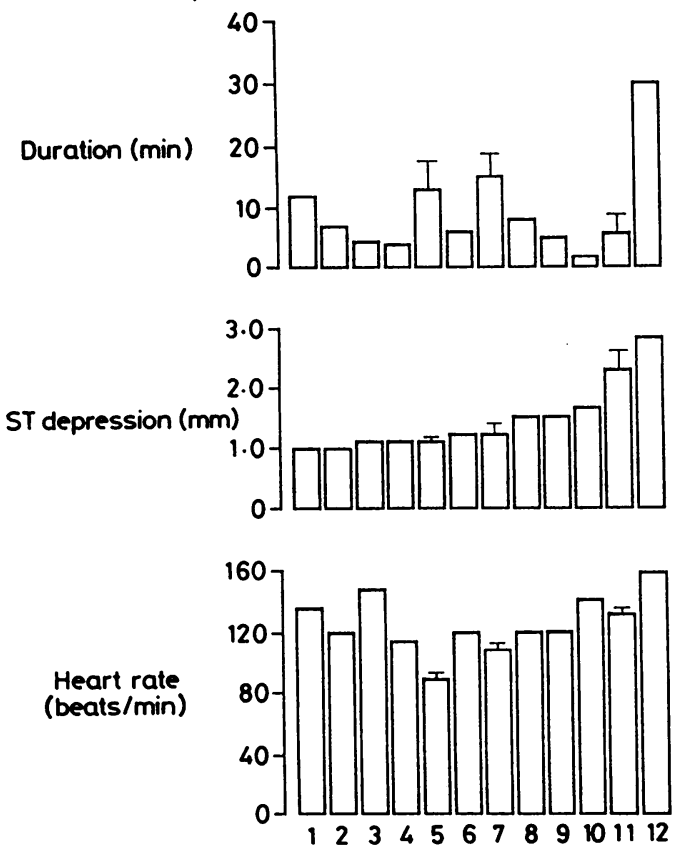

Fig 4 Histograms showing the maximal heart rate, maximal ST depression, and duration of the episodes in individual subjects (mean (SEM)).

Before we can draw conclusions about the degree and incidence of "silent myocardial ischaemia" from ambulatory tape recordings we need to know the behaviour of the ST segment in normal subjects under ambulant conditions. The results of several studies were conflicting, with reports of significant ST segment depression in $0 \%,{ }^{28} 2.5 \%,{ }^{11} 8.3 \%$, ${ }^{9}$ and $30 \%$ of subjects and of ST segment elevation in $0 \%,{ }^{28} 5 \%,{ }^{11} 23 \%$, ${ }^{9}$ and $0 \%{ }^{10}$ of subjects respectively.

Several factors could have contributed to this wide variation in results. The most obvious is subject selection; in addition to a pronounced occupational bias in three of the studies, ${ }^{9-11}$ the group studied by Armstrong et al ${ }^{10}$ was older than that of Quyyumi et $a l^{9}$ or Deanfield et al. ${ }^{11}$ In the last two studies, ST elevation was associated with the younger subjects, but important ST depression had no clear association with age. In the present study we attempted to minimise bias by selecting subjects randomly from a general population and including those aged from 20 to 70 years.

Method differences may also have contributed to the spread of results. Two studies used Avionics direct mode recorders, ${ }^{1028}$ whereas we, Quyyumi et $a l,{ }^{9}$ and Deanfield et al ${ }^{11}$ used frequency modulated recorders to avoid possible distortion of the ST-T segment. Armstrong et al made recordings on lead
$\mathrm{CH} 6,{ }^{10}$ whereas the other studies used CM5 as the lateral lead. Two groups used CM2 as an auxiliary lead and found it to be less sensitive than CM5 for the detection of ST-T changes. ${ }^{911}$ In common with Armstrong et $a l,{ }^{10}$ we recorded CC5 as an auxiliary lead. We found it less sensitive than CM5 for detecting ST depression but more sensitive for detecting ST elevation.

In the four earlier studies, the reported incidence of ambulatory ST changes included subjects with postural and exercise induced ST depression. Moreover, orthostatic and exercise tests were performed only on subgroups of volunteers chosen either at random, ${ }^{10}$ or by age ${ }^{11}$ or because of significant ambulatory ST changes. ${ }^{9}$ In the present study screening of all subjects before the study ensured that the 12 subjects with significant ambulatory ST depression and the nine with ST elevation were free of orthostatic or exercise induced ST segment changes. Such screening would have substantially altered the results of the previous studies, particularly that of Armstrong et al..$^{10}$

Finally (and perhaps most importantly), though the previous studies all used the same definition of significant ST segment depression, the criteria for episodes were not the same. In particular, Deanfield et al excluded any episodes in which baseline instability caused the ST depression to appear intermittent. ${ }^{11}$ This strict criterion may account for the low incidence of ST depression reported by that group, since in our study almost all episodes of ST depression were accompanied by tachycardia and some baseline instability. Because we were using computer averaged measurements we were confident of the objectivity of our baseline and of the threshold values for detection of episodes. In addition, both observers also had to agree on the visual scoring of each electrocardiographic strip printout before it was accepted as a genuine episode.

There is disagreement about the duration of episodes of ST segment elevation and depression. Our findings agree with previous reports that ST elevation usually occurs at night and at relatively low heart rates. Whereas some workers reported episodes of ST elevation lasting several hours, ${ }^{911}$ we saw well defined bursts of ST elevation lasting only a few minutes. This disagreement may arise because other workers did not take into account the slow noctural upward baseline shift. We did not find any episodes of ST depression during sleep; all were related to increased heart rates during activities like jogging, cycling, car driving, and smoking recorded on the subjects' diary cards. The incidence of $T$ wave changes in our study accorded with that of Armstrong et al, ${ }^{10}$ whereas others have reported T wave changes in over half their subjects. ${ }^{11}$ 


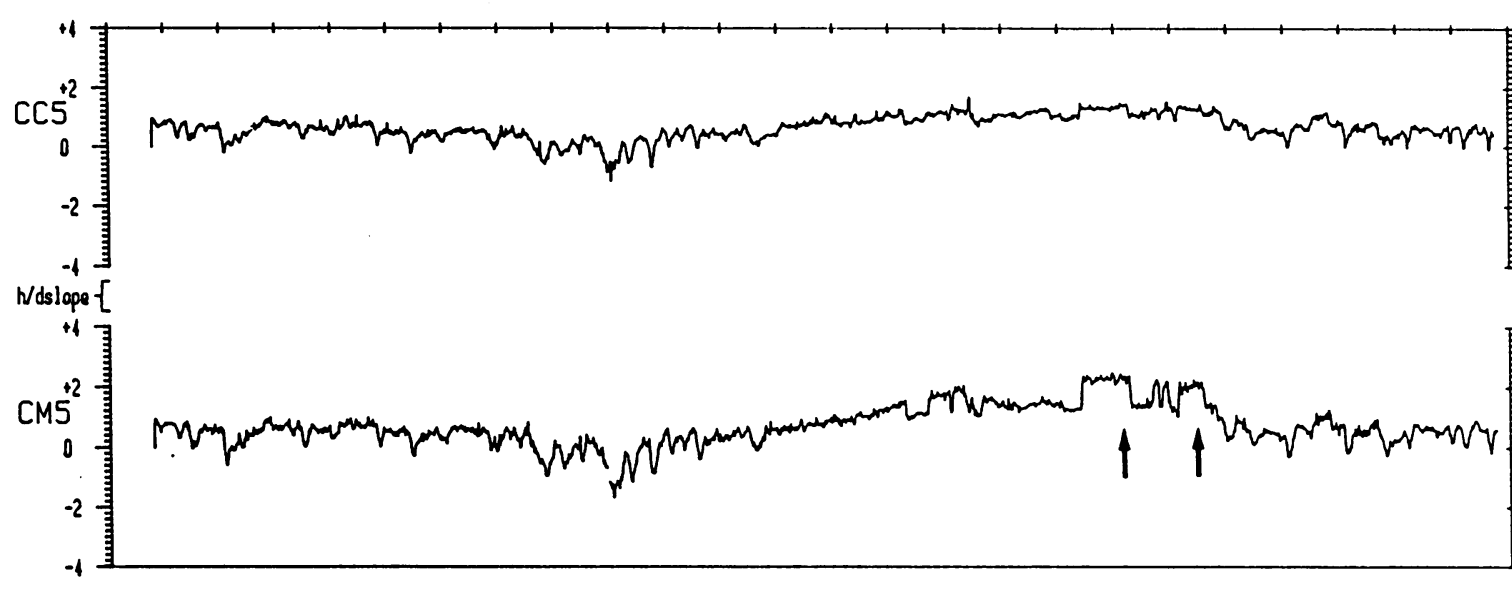

$$
\text { Wrenth } f
$$
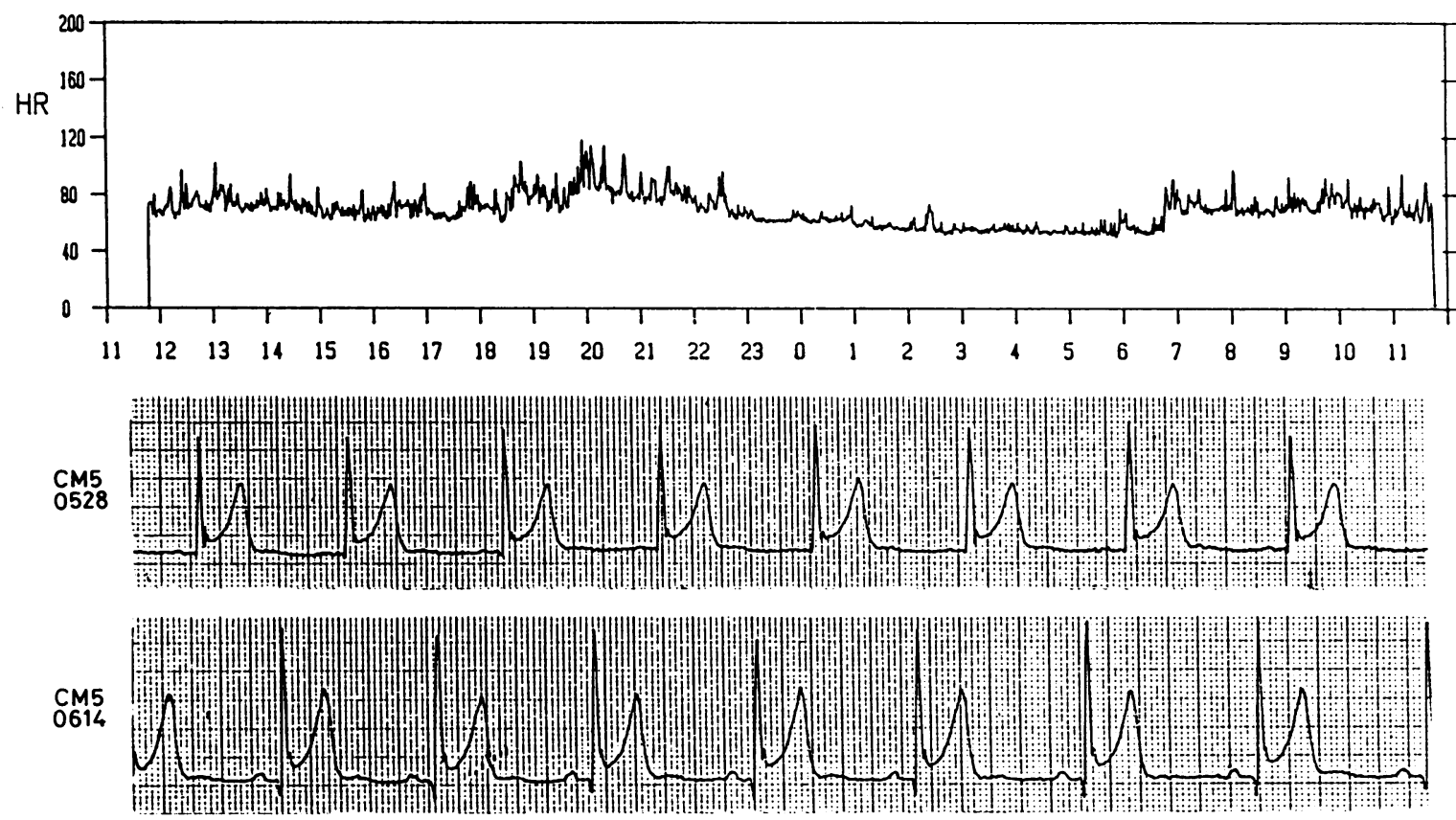

Fig 524 hour trend chart showing a gradually rising baseline at night, most apparent in CM5, with distinct episodes of ST elevation superimposed. These occurred during sleep at a heart rate of 53-55 beats/min.

False positive exercise responses in normal people are well documented ${ }^{29}{ }^{30}$ but we were careful to separate out all subjects with positive exercise responses because they might have occult obstructive coronary disease. Despite our stringent exclusion criteria we saw significant ambulatory ST segment elevation and depression in $9^{\circ}{ }_{0}$ and $12^{\circ}{ }_{0}$ of our subjects respectively. Coronary arteriography wa\& not warranted in these symptom free healthy volun $\overrightarrow{\mathbb{D}}$ teers, but where possible people with abnormal $S \frac{P_{0}}{}$ segment depression were investigated by exercise thallium imaging and exercise radionuclide ven 
No of episodes 122522512252
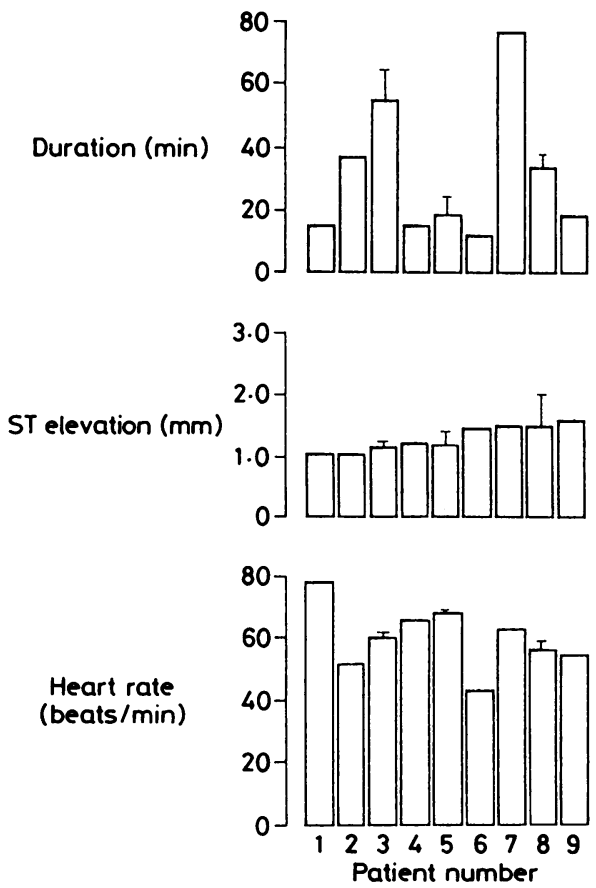

Fig 6 Histograms showing the heart rate, maximal $S T$ elevation, and duration of the episodes in all subjects with $S T$ elevation.

triculography. We found no evidence of significant "occult" obstructive coronary artery disease. Although the ventriculograms detected some impairment of function, our final reference standard of normality was the thallium scan, since this has the greatest diagnostic and prognostic sensitivity for coronary artery disease. ${ }^{3132}$

One 33 year old woman had a reversible perfusion defect in the redistribution phase of the thallium scan in the region of the upper interventricular septum. Her radionuclide angiogram was normal and she was symptom free; we therefore did not think that coronary angiography was justifiable. This woman has remained symptom free for a further two years.

In people with ST segment elevation, coronary vasospasm may have contributed to our findings. But we did not consider it ethical to proceed to provocative testing with cold pressor $^{33}$ or ergometrine maleate, ${ }^{34}{ }^{35}$ since both tests would require coronary arteriography and are of unproven value particularly in symptom free "normal" subjects. These subjects remained symptom free during the two year follow up.

It is interesting that the results of radionuclide testing were broadly the same in people with an abnormal exercise electrocardiographic response and in those with normal exercise responses but ST depression on ambulatory monitoring. In both groups the thallium scans were normal (with one possible exception), while approximately half the ventriculograms showed evidence of functional impairment. This group may represent a very early stage of coronary artery disease; only long term follow up will confirm or refute this notion.

"False positive" ambulatory ST changes have been described by several workers, but because of method limitations it has been impossible to separate genuine ST deviations from artefact. The ST changes observed in our study are unlikely to be artefactual because we validated the accuracy of each individual recording and also took the nocturnal change in the baseline into account in the tape analysis. The subjects who were restudied showed consistent ST baseline levels and repeatable ST changes. A total of 22 subjects showed ST segment abnormalities either during exercise or during monitoring; we were able to perform exercise thallium scans in 14 , and 13 of these were normal. In

Table 3 Results of radionuclide testing in eight people who had shown $S T$ changes during ambulatory recording (groups A2, $A 3, A 4$, fig 1)

\begin{tabular}{|c|c|c|c|c|c|c|c|c|c|}
\hline \multirow{2}{*}{$\begin{array}{l}\text { Case } \\
\text { No }\end{array}$} & \multirow[b]{2}{*}{ Sex } & \multirow{2}{*}{$\begin{array}{l}\text { ST } \\
\text { change }\end{array}$} & \multicolumn{2}{|c|}{$L V E F\left("{ }_{0 \prime}\right)$} & \multicolumn{2}{|c|}{$P F R(E D V / s)$} & \multicolumn{2}{|c|}{ Wall motion score } & \multirow{2}{*}{$\begin{array}{l}\text { Thallium } \\
\text { score }\end{array}$} \\
\hline & & & Rest & Exercise & Rest & Exercise & Rest & Exercise & \\
\hline $\begin{array}{l}1 \\
2 \\
3\end{array}$ & $\begin{array}{l}F \\
F \\
F\end{array}$ & $\begin{array}{l}\text { D } \\
\text { D } \\
\text { D }\end{array}$ & $\begin{array}{l}55 \\
54 \\
50\end{array}$ & $\begin{array}{l}49 \\
46 \\
68\end{array}$ & $\begin{array}{l}1 \cdot 2 \\
3 \cdot 2 \\
2 \cdot 1\end{array}$ & $\begin{array}{l}5 \cdot 5 \\
4 \cdot 1 \\
5 \cdot 7\end{array}$ & $\begin{array}{l}0 \\
1 \\
0\end{array}$ & $\begin{array}{l}0 \\
1 \\
0\end{array}$ & $\begin{array}{l}0 \\
0 \\
\text { Reversible } \\
\quad \text { septal defect }\end{array}$ \\
\hline $\begin{array}{l}4 \\
5 \\
6 \\
7 \\
8\end{array}$ & $\begin{array}{l}\mathrm{F} \\
\mathrm{F} \\
\mathrm{M} \\
\mathrm{M} \\
\mathrm{M}\end{array}$ & $\begin{array}{l}D \\
D \\
D+E \\
D \\
E\end{array}$ & $\begin{array}{l}51 \\
69\end{array}$ & $\begin{array}{l}\star \\
\star \\
59 \\
75\end{array}$ & $\begin{array}{l}1.98^{1} \\
2 \cdot 3^{1}\end{array}$ & $\begin{array}{l}\star \\
\star \\
\star \\
7 \cdot 0\end{array}$ & $\begin{array}{l}0 \\
0 \\
0 \\
0 \\
0\end{array}$ & $\begin{array}{l}0 \\
0 \\
0 \\
0 \\
0\end{array}$ & $\begin{array}{l}0 \\
0 \\
0 \\
0 \\
0\end{array}$ \\
\hline
\end{tabular}

*Data could not be recovered because of disk corruption; however, all values were reported as normal at the time of acquisition.

LVEF, Icft ventricular ejection fraction; D, ST depression present on ambulatory recording; E, ST elevation present on ambulatory recording; PFR, peak filling rate; $\mathrm{EDV} / \mathrm{s}$, end diastolic volumes per second. 
Table 4 Results of radionuclide testing in seven out of ten people who had shown a positive electrocardiographic response during exercise (group B, fig 1)

\begin{tabular}{|c|c|c|c|c|c|c|c|c|}
\hline \multirow{2}{*}{$\begin{array}{l}\text { Case } \\
\text { No }\end{array}$} & \multirow[b]{2}{*}{$\operatorname{Sex}$} & \multicolumn{2}{|c|}{$L V E F\left(o_{0}\right)$} & \multicolumn{2}{|c|}{$P F R(E D V / s)$} & \multicolumn{2}{|c|}{ Wall motion score } & \multirow{2}{*}{$\begin{array}{l}\text { Thallium } \\
\text { score }\end{array}$} \\
\hline & & Rest & Exercise & Rest & Exercise & Rest & Exercise & \\
\hline $\begin{array}{r}9 \\
10 \\
11 \\
12 \\
13 \\
14 \\
15\end{array}$ & $\begin{array}{l}\mathbf{F} \\
\mathbf{F} \\
\mathbf{M} \\
\mathbf{M} \\
\mathbf{M} \\
\mathbf{M} \\
\mathbf{M}\end{array}$ & $\begin{array}{l}64 \\
61 \\
68 \\
69 \\
65 \\
66 \\
61\end{array}$ & $\begin{array}{l}59 \\
62 \\
80 \\
76 \\
73 \\
62 \\
57\end{array}$ & $\begin{array}{l}2.0 \\
2.7 \\
2.6 \\
2.6 \\
3.4 \\
2.7 \\
2.4\end{array}$ & $\begin{array}{l}4 \cdot 8 \\
7 \cdot 6 \\
4 \cdot 2 \\
6 \cdot 8 \\
6 \cdot 3 \\
2 \cdot 3 \\
5 \cdot 8\end{array}$ & $\begin{array}{l}0 \\
0 \\
0 \\
0 \\
0 \\
0 \\
0\end{array}$ & $\begin{array}{l}0 \\
0 \\
0 \\
0 \\
0 \\
0 \\
0\end{array}$ & $\begin{array}{l}0 \\
0 \\
0 \\
0 \\
0 \\
0 \\
-\end{array}$ \\
\hline
\end{tabular}

LVEF, left ventricular ejection fraction; PFR, peak filling rate; EDV/s, end diastolic volumes per second.

Table 5 Analysis of variance: ST baseline values in 20 people with recordings on two occasions

\begin{tabular}{|c|c|c|c|c|c|c|c|c|}
\hline Variable & No & $\begin{array}{l}\text { Overall } \\
\text { mean }\end{array}$ & $\sigma_{s}$ & $\sigma$ & $F=\left(\sigma_{s} / \sigma\right)^{2}$ & $\begin{array}{l}d f \\
\text { of } \sigma_{s}\end{array}$ & $\begin{array}{l}d f \\
\text { of } \sigma\end{array}$ & $p$ \\
\hline $\begin{array}{c}\text { CM5 baseline: } \\
\text { Day (mm) } \\
\text { Night }(\mathrm{mm})\end{array}$ & $\begin{array}{l}20 \\
20\end{array}$ & $\begin{array}{r}-0.13 \\
+0.31\end{array}$ & $\begin{array}{l}0.40 \\
0.55\end{array}$ & $\begin{array}{l}0 \cdot 14 \\
0 \cdot 15\end{array}$ & $\begin{array}{r}8 \cdot 16 \\
13 \cdot 44\end{array}$ & $\begin{array}{l}19 \\
19\end{array}$ & $\begin{array}{l}39 \\
39\end{array}$ & $\begin{array}{l}<0.001 \\
<0.001\end{array}$ \\
\hline $\begin{array}{l}\text { CC5 baseline: } \\
\text { Day (mm) } \\
\text { Night }(\mathrm{mm})\end{array}$ & $\begin{array}{l}17 \\
17\end{array}$ & $\begin{array}{l}+0.05 \\
+0.22\end{array}$ & $\begin{array}{l}0.20 \\
0.22\end{array}$ & $\begin{array}{l}0.08 \\
0.11\end{array}$ & $\begin{array}{l}6 \cdot 25 \\
4 \cdot 00\end{array}$ & $\begin{array}{l}16 \\
16\end{array}$ & $\begin{array}{l}33 \\
33\end{array}$ & $\begin{array}{l}<0.001 \\
<0.001\end{array}$ \\
\hline
\end{tabular}

Comparison of mean values for day and night.

CM5: SE of the difference $=0.046, t=(0.31+0.13) / 0.046=9.56, \mathrm{df}=38, \mathrm{p}<0.001$

CC5: $S E$ of the difference $=0.032, t=(0.22-0.05) / 0.032=5.31, d f=32, p<0.001$.

$\sigma_{\mathrm{s}}$, component of variability between subjects; $\sigma$, component of variability between recording occasions; df, degrees of freedom.

Table 6 Analysis of variance: episodes of ST depression in 20 people with recordings on two occasions

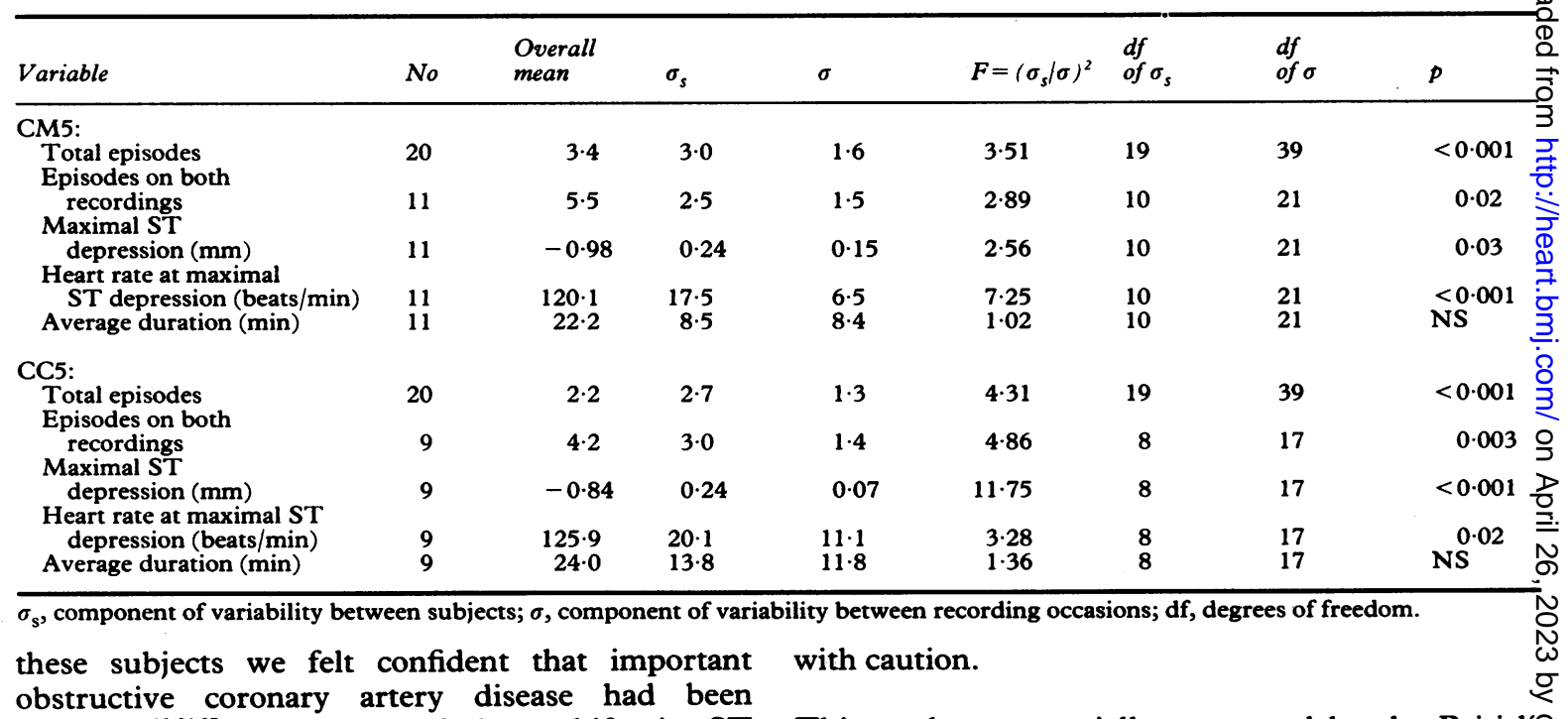

excluded. ${ }^{123637}$ The cause of these shifts in ST segment at all ages and in both sexes remains to be established.

The clinical implications of our findings are important in view of the current emphasis on screening of the population for "occult" or "silent" coronary artery disease and we feel that the results of such screening investigations should be interpreted
This study was partially supported by the Britishe Heart Foundation. We thank Ms C Dore for statistical assistance.

\section{References}

1 Selwyn AP, Fox K, Eves M, Oakley D, Dargie H, Shillingford J. Myocardial ischaemia in patients withe 
frequent angina pectoris. $\mathrm{Br} \mathrm{Med} J$ 1978;ii:1594-6.

2 Allen RD, Gettes LS, Phalan C, Avington MD. Painless ST-segment depression in patients with angina pectoris. Chest 1976;69:467-73.

3 Cecchi AC, Dovellini EV, Marchi F, Pucci P, Santoro GM, Fazzini PF. Silent myocardial ischaemia during ambulatory electrocardiographic monitoring in patients with effort angina. J Am Coll Cardiol 1983;1:934-9.

4 Deanfield JE, Selwyn AP, Chierchia S, et al. Myocardial ischaemia during daily life in patients with stable angina: its relation to symptoms and heart rate changes. Lancet 1983;i:753-8.

5 Schang SJ Jr, Pepine CJ. Transient asymptomatic ST segment depression during daily activity. Am J Cardiol 1977;39:396-402.

6 Lachman AB, Semler HJ, Gustafson RH. Postural $S T-T$ wave changes in the radioelectrocardiogram simulating myocardial ischaemia. Circulation 1965; 31:557-63.

7 Taggart P, Parkinson P, Carruthers M. Cardiac responses to thermal, physical and emotional stress. Br Med J 1972;iii:71-6.

8 Bala Subramanian V, Davies AB, Bowles MJ, Raftery EB. Ambulatory ST segment monitoring with frequency modulated tape recorders. A review. In: Stott FD, Raftery EB, Clement DL, Wright SL, eds. ISAM-GENT 1981. Proceedings of the fourth international symposium on ambulatory monitoring. London: Academic Press, 1982:52-61.

9 Quyyumi AA, Wright C, Fox K. Ambulatory electrocardiographic ST segment changes in healthy volunteers. Br Heart J 1983;50:460-4.

10 Armstrong WF, Jordan JW, Morris SN, McHenry PL. Prevalence and magnitude of $S-T$ segment and $\mathrm{T}$-wave abnormalities in normal men during continuous ambulatory electrocardiography. $\mathrm{Am} \mathrm{J}$ Cardiol 1982;49:1638-42.

11 Deanfield JE, Ribiero P, Oakley K, Krikler S, Selwyn AP. Analysis of ST-segment changes in normal subjects: implications for ambulatory monitoring in angina pectoris. Am J Cardiol 1984;54:1321-5.

12 O'Hara MJ, Lahiri A, Whittington JR, Crawley JCW, Raftery EB. Detection of high risk coronary artery disease by thallium imaging. $B r$ Heart $J$ 1985;53: 616-23.

13 Lahiri A, Rodrigues EA, Al-Khawaja I, Raftery EB. Effects of a new vasodilating beta-blocker (Carvedilol) on left ventricular function in stable angina pectoris. Am J Cardiol 1987;59:769-74.

14 Hains ADB, Al-Khawaja I, Hinge DA, Lahiri A, Raftery EB. Radionuclide left ventricular ejection fraction: a comparison of three methods. Br Heart $J$ 1987;57:242-6.

15 Bonow RO, Bacharach SL, Green MV. Impaired left ventricular diastolic filling in patients with coronary artery disease: assessment with radionuclide angiography. Circulation 1981;64:315-23.

16 Mancini GBJ, Slutsky RA, Norris SL, Bhargava V, Ashburn WL, Higgins CB. Radionuclide analysis of peak filling rate, filling fraction and time to peak filling rate. Response to supine bicycle exercise in normal subjects and patients with coronary artery disease.
Am J Cardiol 1983;51:43-51.

17 Holter NJ. New method for heart studies. Science 1961;134:1214-20.

18 Bragg-Remschel DA, Anderson CM, Winkle RA. Frequency response characteristics of ambulatory ECG monitoring systems and their implications for ST segment analysis. Am Heart J 1982;103:20-31.

19 Balasubramanian V, Lahiri A, Green HL, Stott FD, Raftery EB. Ambulatory ST segment monitoring: problems, pitfalls, solutions, and clinical application. Br Heart J 1980;44:419-25.

20 Carboni GP, Lahiri A, Cashman PMM, Raftery EB. Ambulatory heart rate and ST-segment depression during painful and silent myocardial ischaemia in chronic stable angina. Am J Cardiol 1987;59: 1029-34.

21 Von Arnim T, Höfling B, Schreiber M. Characteristics of episodes of ST elevation or ST depression during ambulatory monitoring in patients subsequently undergoing coronary angiography. $\mathrm{Br}$ Heart $J$ 1985;54:484-8.

22 Redwood DR, Borer JS, Epstein SE. Whither the ST segment during exercise? Circulation 1976;54:703-6.

23 Taggart P, Carruthers M, Somerville W. Electrocardiogram, plasma catecholamines and lipids and their modification by oxprenolol when speaking before an audience. Lancet 1973;ii:341-6.

24 Levy N, Abinader E. Continuous-electrocardiography monitoring with Holter electrocardiocorder throughout all stages of gastroscopy. Am J Dig Dis 1977; 22:1091-6.

25 Stern S, Tzivoni D, Stern Z. Diagnostic accuracy of ambulatory ECG monitoring in ischaemic heart disease. Circulation 1975;52:1045-9.

26 Tzivoni D, Stern Z, Keren A, Stern S. Electrocardiographic characteristics of neurocirculatory asthenia during everyday activities. $\mathrm{Br}$ Heart $J$ 1980;44:426-32.

27 Taggart P, Gibbons D, Somerville W. Some effects of motor-car driving on the normal and abnormal heart. Br Med J 1969;iv:130-4.

28 Stern S, Tzivoni D. Dynamic changes in the ST-T segment during sleep in ischaemic heart disease. $A m \mathrm{~J}$ Cardiol 1973;32:17-20.

29 Borer JS, Brensike JF, Redwood DR. Limitations of the electrocardiographic response to exercise in predicting coronary-artery disease. $N$ Engl J Med 1975; 293:367-71.

30 Froehlicher VF, Yanowitz FG, Thomson AS, Lancaster MC. The correlation of coronary arteriography and the electrocardiographic response to maximal treadmill testing in 76 asymptomatic men. Circulation 1973;48:597-604.

31 Gibson RS, Watson DD, Craddock GB, et al. Prediction of cardiac events after uncomplicated myocardial infarction: a prospective study comparing predischarge exercise thallium-201 scintigraphy and coronary angiography. Circulation 1983;68:321-36.

32 Wackers FJ, Russo DJ, Russo D, Clements JP. Prognostic significance of normal quantitative planar thallium-201 stress scintigraphy in patients with chest pain. J Am Coll Cardiol 1985;6:27-30.

33 Jones RI, Lahiri A, Cashman PMM, Dore C, Raftery 
EB. Left ventricular function during isometric hand grip and cold stress in normal subjects. Br Heart $J$ 1986;55:246-52.

34 Schwartz JS, Kaufmann L. Performance of ergonovine provocative testing for coronary artery spasm. Health and Public Policy Committee, American College of Physicians. Ann Intern Med 1984;100:151-2.

35 Curry RC, Pepine CJ, Sabom MB, Feldman RL, Christie LG, Conti CR. Effects of ergonovine in patients with and without coronary artery disease.
Circulation 1977;56:803-9.

36 Kaul S, Newell JB, Chesler DA, et al. Value of computer analysis of exercise thallium images in the noninvasive detection of coronary artery disease.. JAMA 1986;255:508-11.

37 Canhasi B, Dae M, Botvinick E, et al. Interaction of 'supplementary' scintigraphic indicators of ischaemia? and stress electrocardiography in the diagnosis of $\frac{\bar{G}}{\bar{N}}$. multivessel coronary disease. J Am Coll Cardiol $\frac{\text { D }}{\Phi}$ 1985;6:581-8. 